\title{
Complementary techniques for solid oxide electrolysis cell characterisation at the micro- and nano-scale
}

\author{
D. Wiedenmann ${ }^{a, b, *}$, A. Hauch ${ }^{c}$, B. Grobéty ${ }^{a}$, M. Mogensen ${ }^{c}$, U.F. Vogt ${ }^{b, d}$ \\ ${ }^{a}$ Department of Geosciences, University of Fribourg, Pérolles, 1700 Fribourg, Switzerland \\ ${ }^{\mathrm{b}}$ EMPA, Swiss Federal Laboratories for Materials Testing and Research, Department of Mobility, Division Hydrogen \& Energy, \\ Ueberlandstrasse 129, 8600 Duebendorf, Switzerland \\ ${ }^{\mathrm{c}}$ Fuel Cell and Solid State Division, Risø National Laboratory for Sustainable Energy, Technical University of Denmark, 4000 Roskilde, \\ Denmark \\ ${ }^{\mathrm{d}}$ University of Freiburg, Department of Crystallography, 79104 Freiburg, Germany
}

\begin{abstract}
High-temperature steam electrolysis by solid oxide electrolysis cells (SOEC) is a method with great potential for transforming clean and renewable energy from non-fossil sources to synthetic fuels such as hydrogen, methane or dimethyl ether, which have been identified as promising alternative energy carriers. With the same technology, fuel gas can be used in a very efficient way to reconvert chemically stored energy into electrical energy, since SOECs also work in the reverse mode, operating as solid oxide fuel cells (SOFC). As solid oxide cells $(\mathrm{SOC})$ perform at high-temperatures $\left(700-900{ }^{\circ} \mathrm{C}\right)$, material degradation and evaporation can occur, e.g., from the cell-sealing material, leading to poisoning effects and aging mechanisms that decrease the cell efficiency and long-term durability. To investigate such cell degradation processes, thorough examination of SOCs often requires a chemical and structural characterisation at a microscopic and nanoscopic level. The combination of different microscopic techniques such as conventional scanning electron microscopy (SEM), electron probe microanalysis (EPMA) and the focused ion beam (FIB) preparation technique for transmission electron microscopy (TEM) allows for post-mortem analysis at a multi-scale level. These complementary techniques can be used to characterise structural and chemical changes over a large and representative sample area (microscale) as well as at the nano-scale level for selected sample details. This article presents a methodical approach for the structural and chemical characterisation of changes in aged cathode-supported electrolysis cells produced at Ris $\varnothing$ DTU, Denmark. Additionally, we present results from the characterisation of impurities at the electrolyte/hydrogen interface caused by evaporation of sealing material.
\end{abstract}

\section{Introduction}

Over the last decades, there has been growing interest and increasing research and development work in the field of solid oxide fuel cells (SOFC) and solid oxide electrolysis cells (SOEC) $[1,3,9,13,14]$. SOECs have the potential to provide inexpensive future energy carriers like hydrogen and synthesis gas $[2,15,16,18,20,22]$, using electricity from renewable energy

\footnotetext{
* Corresponding author at: EMPA, Division Hydrogen \& Energy, Ueberlandstrasse 129, CH-8600 Duebendorf, Switzerland. Tel.: +41 (0) 44 8234862; fax: +41 (0) 448234022 .

E-mail address: daniel.wiedenmann@empa.ch (D. Wiedenmann).
} 
sources such as solar energy, geothermal energy and wind power $[10,16,21]$. In the ideal case, surplus energy from, e.g., wind turbines can be stored chemically for later use in fuel cells, thereby increasing the application of renewable energy sources to meet the globally rising demand for energy.

Research and development efforts are focused on moving the SOFC/SOEC technology from a laboratory to an industry scale and developing commercial products with high performance and long-term stability. Because the price of the produced energy is inversely proportional to the performance of the cells [10], it is essential to maximise the material performance and to reduce aging processes.

Besides structural and chemical changes (e.g., phase changes), the precipitation of small amounts of impurities can be detrimental to the performance of the cell. In particular, impurities located at the triple-phase boundaries (TPB) of electrodes have been shown to be crucial for the long-term efficiency of the cell $[7,12]$. These TPBs play an important role in the cell performance as they are the main points of reaction, i.e., the points at which the electron-conductive Ni grains, the oxygenconductive 8YSZ grains and the free pores, through which fuel gas enters and leaves the reaction site, meet. Blocking of these TPBs by precipitated impurities leads to an unacceptable increase in the resistance of the cell. Such impurities found in SOC electrodes are typically at the nano-scale level [12].

The SOECs used for this study were $4 \mathrm{~cm} \times 4 \mathrm{~cm}$ planar cells, which means that, from a microscopic point of view, large cell regions had to be investigated. Therefore, when performing post-mortem microscopy investigation on the tested cells, it is necessary to consider complementary analytical techniques ranging from micro- to nano-scale analysis. Techniques such as SEM and EPMA are useful for a representative qualitative overview of the bulk sample when investigating larger cell regions. Other techniques such as FIB and STEM/TEM can be used to focus the analysis on sitespecific features at the nano-scale level. Furthermore, it is important for post-mortem analysis of SOCs to include both information regarding long-term structural changes and detailed information on the chemical composition of, e.g., impurities to identify possible sources of contamination.

In this study, we focus on post-mortem analysis of a longterm degraded SOEC. A single cell was tested for $1500 \mathrm{~h}$ during which a significant loss in the cell performance was observed as a definite increase in the cell resistance. We applied SEM for structural investigation at the micro-scale and STEM for sitespecific characterisation at the nano-scale. FIB was used as a preparation tool to provide electron transparent specimens in the form of TEM lamellae. To investigate the chemical distribution of the bulk sample at the micro-scale level, a wavelength dispersive spectroscopy (WDS) method was used, whereas the chemical composition of the nano-scale impurities was determined by energy dispersive spectroscopy (EDS) on a TEM lamella.

\section{Experimental}

\subsection{Cell assembly and testing procedure}

The investigated cathode-supported SOECs are full cells produced at Ris $\varnothing$ DTU. They are composed of a 10- to $15-\mu \mathrm{m}$-thick hydrogen electrode (cathode) of Ni/8YSZ composite, a 10- to 15$\mu \mathrm{m}$-thick 8YSZ ceramic electrolyte and a 15- to 20- $\mu \mathrm{m}$-thick LSM/ 8YSZ composite oxygen electrode (anode). A 300- $\mu$ m-thick Ni/ YSZ layer supports the cells mechanically on the hydrogen side. A reference cell (not tested under current load) and a cell tested under galvanostatic electrolysis conditions were investigated. The tested cell was operated for $1500 \mathrm{~h}$ in total and for several hundred hours under different electrolysis conditions. Cell voltage measurements, electrochemical impedance spectroscopy and EDS showed clear signs of degradation [7].

\subsection{Simulated $\mathrm{X}$-ray spectral analyses}

For simulated qualitative energy dispersive spectroscopy (EDS) on bulk samples, the program MA-Table from Frank Eggert was applied (http://www.microanalyst.net). A standard Si detector with 150-eV resolution (FWHM of $\mathrm{Mn} \mathrm{K \alpha}$ ) with a detector thickness of $3 \mathrm{~mm}$ was chosen.

\subsection{Electron probe microanalysis (EPMA)}

EPMA measurements are generally used for qualitative and quantitative chemical analysis of materials, with a spatial resolution in the micron range. In contrast to energy dispersive spectroscopy (EDS), EPMA takes advantage of the wave nature of photons to separate characteristic X-rays by Bragg diffraction using different analyser crystals. Therefore, the peak-to-background ratio and the spectral resolution of WDS are much higher as compared to EDS. This leads to more precise quantification, smaller errors and much lower detection limits when working with bulk samples. The cells were cut in a cross-section geometry and cold impregnated with the polymer system Araldit BY158/Aradur 21 to completely fill up the interconnected pore space of the electrodes. The resin was infiltrated into the sample at $20 \mathrm{mbar}$. After $50 \mathrm{~min}$, a pressure of 2 bars was applied in order to allow the polymer to penetrate deeper into the pores. The samples were kept for $12 \mathrm{~h}$ at $80^{\circ} \mathrm{C}$ to cure the polymer. The embedded cell pieces were mechanically polished on textile substrates with several diamond suspensions (MetaDi monocrystalline diamond suspensions, Buehler) with a final particle size of $1 \mu \mathrm{m}$. The surface roughness was further reduced by chemical polishing (Masterprep Polishing Suspension 0.05 Micron, Buehler). Finally, the samples were coated with carbon to make the surface electrically conductive. Elemental maps and single point spectra were recorded to obtain qualitative chemical information of the different cell components. A Jeol Superprobe 8800 equipped with four spectrometers was operated at an acceleration voltage of $15 \mathrm{kV}$ and a beam current of $2 \times 10^{-8}$ A. For the element mapping, a $70 \times 70 \mu \mathrm{m}$ area at a pixel size of $1 \mu \mathrm{m}$ was chosen. The dwell time was $4 \mathrm{~s}$ at the respective maximum peak positions. The detection limit for Si-WDS measurements under optimised operation conditions is in the range of $100 \mathrm{ppm}$, which is a tenfold increase over EDS [5].

\subsection{Focused ion beam (FIB) technique and scanning transmission electron microscopy (STEM)}

While the EPMA technique allows for chemical analysis and structural examination at the microscopic level, STEM 
investigations at the nanoscopic level offer the possibility of observing structural and chemical changes at phase boundaries. A challenging problem regarding TEM analysis of SOCs is the preparation of appropriately thin samples as SOCs have rather non-uniform mechanical properties due to their highly porous structure and heterogeneous composition. The electrolyte/hydrogen electrode interface (especially the triplephase boundaries) of aged electrolysis cells has been found to be particularly heterogeneous [7]. These are the most interesting areas concerning the potential deposition of Si impurities. The interface consists of a dense 8YSZ electrolyte layer and a cermet of Ni grains, 8YSZ particles and pores for the hydrogen electrode. The free pore space easily destabilises the composite system if thinned for TEM purposes. Thus, classical TEM sample preparation techniques such as sample prethinning by means of dimpling and subsequent ion milling have been demonstrated to be inappropriate since the described material properties lead to non-uniform thinning and deformation of the thinned TEM samples.

To overcome these problems, site-specific preparation of TEM samples by means of a focused ion beam (FIB) technique $[11,17,19]$, was employed to allow for successful TEM lamella preparation at the electrolyte/fuel electrode interface of the SOECs. The epoxy resin Araldit BY158/Aradur 21, supplied by Huntsman, was used to infiltrate the pores in the hydrogen electrode to stabilise the porous structure as described in the experimental section for the electron probe microanalysis.

In summary, the FIB preparation mainly consists of four steps, which are explained in detail in Fig. 1. The area of interest, e.g., the interface between the electrolyte and the active layer of the fuel electrode, is selected and covered with a Pt surface protection layer (Fig. 1.1). Subsequently, two wedge-shaped boxes are cut out in front and behind the area of interest by sputtering sample material away with a highly focused $\mathrm{Ga}^{+}$beam (Fig. 1.2). In a further step, the emerging lamella is further thinned to a thickness of approx. 200$250 \mathrm{~nm}$. The thickness should not be less than this value to prevent the TEM lamella from becoming destabilised. At the region of highest interest, the sample is subsequently thinned by means of a window technique (Fig. 1.3). In this region, the thickness can be decreased down to approx. $100 \mathrm{~nm}$, i.e., reaching the level generally accessible for homogeneous and dense materials (Fig. 1.4). Subsequently, the as-prepared TEM lamellae were examined by scanning transmission electron microscopy (STEM) and EDS, including qualitative mapping and quantitative point analyses.

For the FIB sample preparation of the lamella shown in Fig. 1, a FEI Strata Dual Beam 235, operated at an acceleration voltage of $30 \mathrm{kV}$ for the $\mathrm{Ga}^{+}$beam and $5 \mathrm{kV}$ for the electron beam, was used. TEM and STEM were carried out with a FEI CM30 $\mathrm{LaB}_{6}$ gun microscope equipped with a Noran detector system for EDS. For the FIB sample preparation of the lamella for which TEM images are shown in Fig. 6, a Zeiss Crossbeam 1540X was used. The TEM images in Fig. 6 were obtained by using a JEM-3000F field emission gun microscope equipped with a Gatan imaging filter. The corresponding quantitative EDS measurements were performed using an INCA EDS microanalysis system from Oxford Instruments (acquisition time of $60 \mathrm{~s}$ ). Quantification was ensured by standardless analysis using the Cliff-Lorimer correction with absorbance.
The calculations were made using the Thermo Fisher NoranSystemSix software package 1.5 .

\section{Results and discussions}

\subsection{Microstructure}

Fig. 2 shows a secondary electron SEM overview image of a polished cross-section of the tested SOEC. As seen in the SEM image, after $1500 \mathrm{~h}$ of operation, there are no major structural changes at the micro-scale that could influence the performance of the cell (e.g., hindered conductivity and intermixing of hydrogen and oxygen caused by cracks in the electrolyte and delamination of the electrodes). The porous electrode structure was able to withstand hundreds of hours of testing, as reported for similar tested SOECs [6]. Furthermore, it can be noted that there is still a visible difference in microstructure between the finer structure of the active layer $(\sim 10-15 \mu \mathrm{m})$ of the hydrogen electrode and the coarser and open structure of the support layer $(\sim 300 \mu \mathrm{m})$.

\subsection{Chemical composition at the micro-scale}

It is well known that the spectral resolution of WDS is far better than that obtained by EDS on bulk samples prepared for conventional SEM investigation [5]. Furthermore, for trace element analyses, WDS is essential due to its low detection limit, i.e., high peak-to-background ratio. However, for composites like the Ni/8YSZ electrode material employed here, quantitative bulk analyses are questionable owing to the fine grained micro-porous and poly-phase material. Due to the non-homogeneous structure of the composite, no adequate standard material for precise quantitative WDS measurements is applicable. Additionally, the interaction volume of the electron beam is larger in porous material as compared to compact material of the same composition. This must be considered for site-specific analyses, as a point measurement may have an interaction volume containing more than one phase (matrix effect). Therefore, we performed thin-film EDS measurements to avoid the matrix effect (see the TEM and EDS section) and to quantitatively analyse impurities.

In the context of qualitative bulk sample analyses, it is especially interesting to compare the detection limits of EDS and WDS for SOC-related materials containing only traces of Si-containing impurities. As an illustration, Fig. 3 shows a set of simulated EDS spectra for a hypothetical cathode material in comparison to a recorded WDS spectrum obtained for the tested SOECs. The hypothetical materials consist of 8YSZ containing 0.1, 1.0 and $10 \mathrm{~mol}_{\%} \mathrm{SiO}_{2}$. The detection limit for $\mathrm{Si}$ corresponds to a $\mathrm{SiO}_{2}$ content in the range of 0.1 to $1 \mathrm{~mol} \%$ for the simulated EDS, influenced by the peak overlap of the $\mathrm{Si}$ $\mathrm{K} \alpha 1$ line and the $\mathrm{Zr} \mathrm{Ll}$ line. In relation to the EDS mapping of a thin lamella for the tested cell (Fig. 5), it seems more relevant to consider the EDS simulations around the Si detection limit (0.1-1.0 $\mathrm{mol} \% \mathrm{SiO}_{2}$ ) as the size of the impurity phase is in the range of $100 \mathrm{~nm} \times 100 \mathrm{~nm} \times 100 \mathrm{~nm} \quad\left(0.001 \mu \mathrm{m}^{3}\right)$ and the sampling volume in a dense material like 8YSZ is in the range of $1 \mu^{3}$ at $10 \mathrm{kV}$, which is typically used for EDS in bulk samples. These rough estimates and this comparison of WDS 

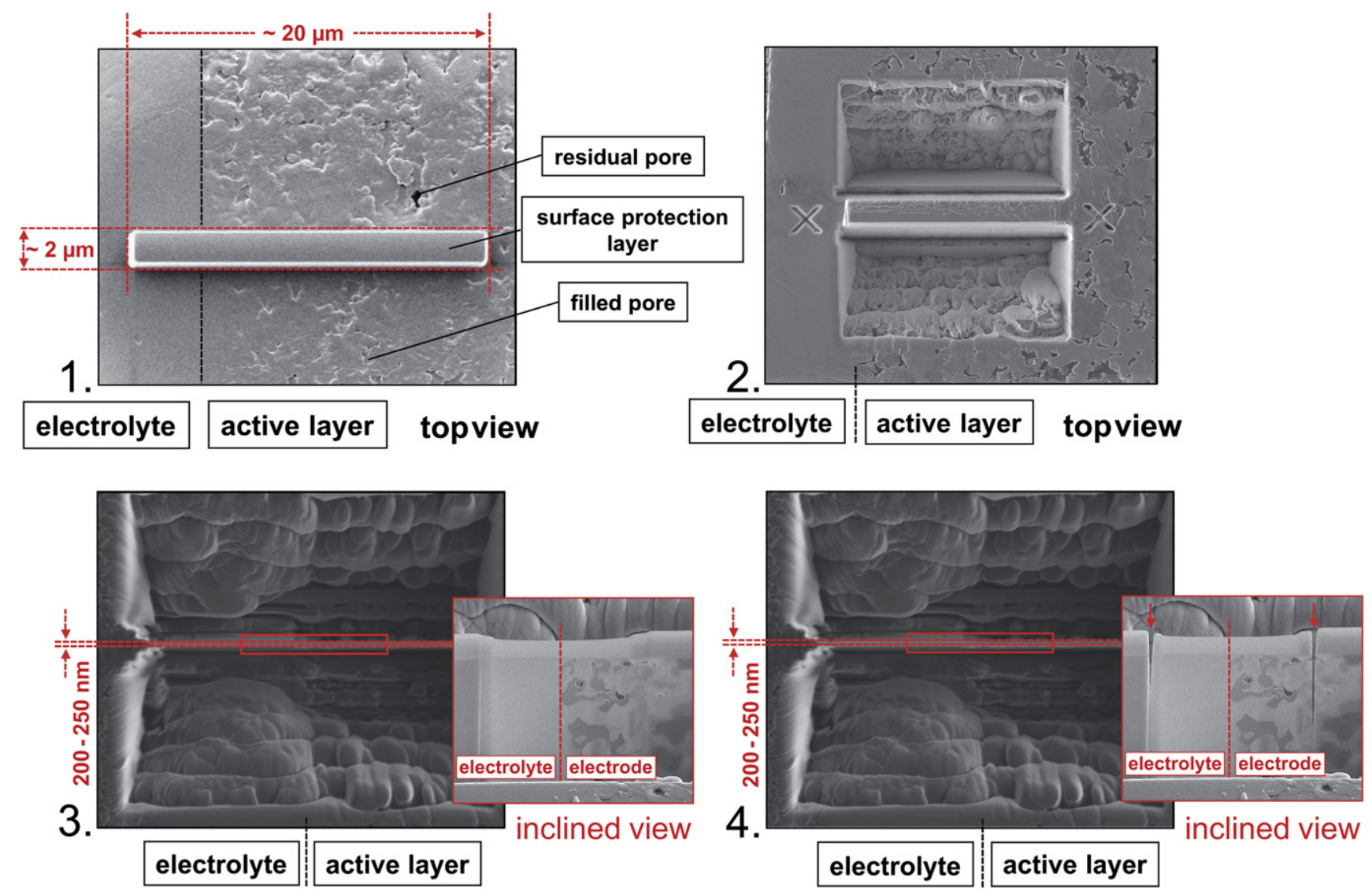

Fig. 1 - Schematic view of the FIB procedure for polymer-infiltrated SOEC materials: The area of interest is selected and protected by a cap layer of Pt (1). Two boxes are cut out by sputtering away adjacent material with a focused $\mathrm{Ga}^{+}$beam (2). Subsequently, the emerging lamella is further thinned to approx. 200-250 $\mathrm{nm}$. Details of high interest are further thinned by locally removing material with a window technique (3). Mechanical stress from thinning is relieved by cutting transections (4). The final average thickness of the as-prepared TEM lamellae is $200-250 \mathrm{~nm}$, and the window thickness is approx. $100 \mathrm{~nm}$ (estimated from an ion image in the FIB).

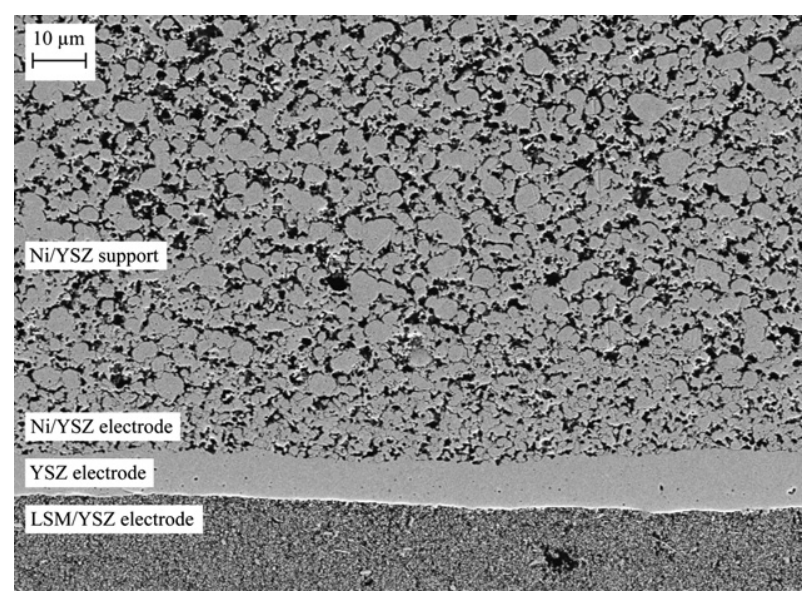

Fig. 2 - Secondary electron SEM image (acc. Voltage: $12 \mathrm{kV}$ ) of the cross-section of the tested SOEC. No significant structural damages at the micro-scale (cracks in the electrolyte, delamination of electrodes, etc.) can be observed. Width of the image: $180 \mu \mathrm{m}$. and EDS for bulk samples for this type of tested cells make it obvious that it may be advantageous to apply WDS to investigate the chemical constituents at the micro-scale for the $\mathrm{Ni} /$ 8YSZ electrode of the tested cell and to be able to scan hundreds of microns of the electrode/electrolyte interface for the presence of traces of impurities.

Point analyses and WDS elemental mappings with high spectral resolution on the electrolysis-tested SOECs were performed. Fig. 4 shows the resulting mapping from WDS measurements of the tested cell (top) and a reference cell (bottom). It is evident from these mappings that Si accumulated at the hydrogen electrode/electrolyte interface, as previously shown by Hauch et al. [7] using EDS. It can be observed that the concentration of $\mathrm{Si}$ is the highest at the hydrogen electrode/electrolyte interface, and the content gradually decreases with increasing distance from this interface. The thickness of the contamination slab determined by WDS mappings is about $20 \mu \mathrm{m}$, which is much thicker than that previously determined by EDS measurements [7]. The difference is due to the much better spectral resolution of the WDS versus the EDS technique as the overlapping peaks ( $\mathrm{Si}$ $\mathrm{K} \propto 1$ and $\mathrm{Zr} \mathrm{Ll}$ ) in the EDS spectra lower the detection limit considerably. Furthermore, it is noted that no Si seems to have 
a

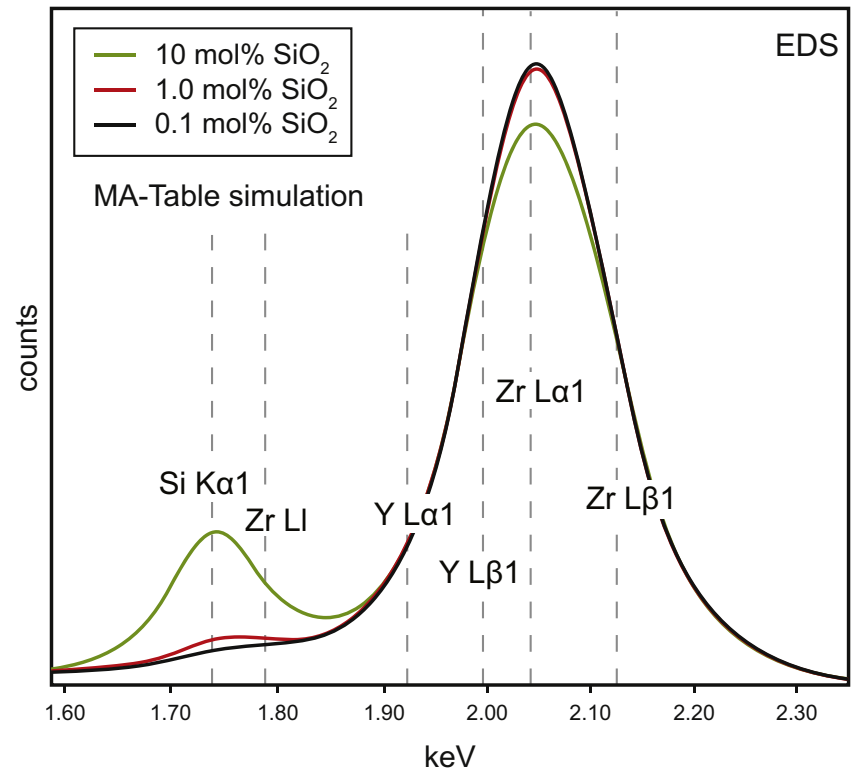

b

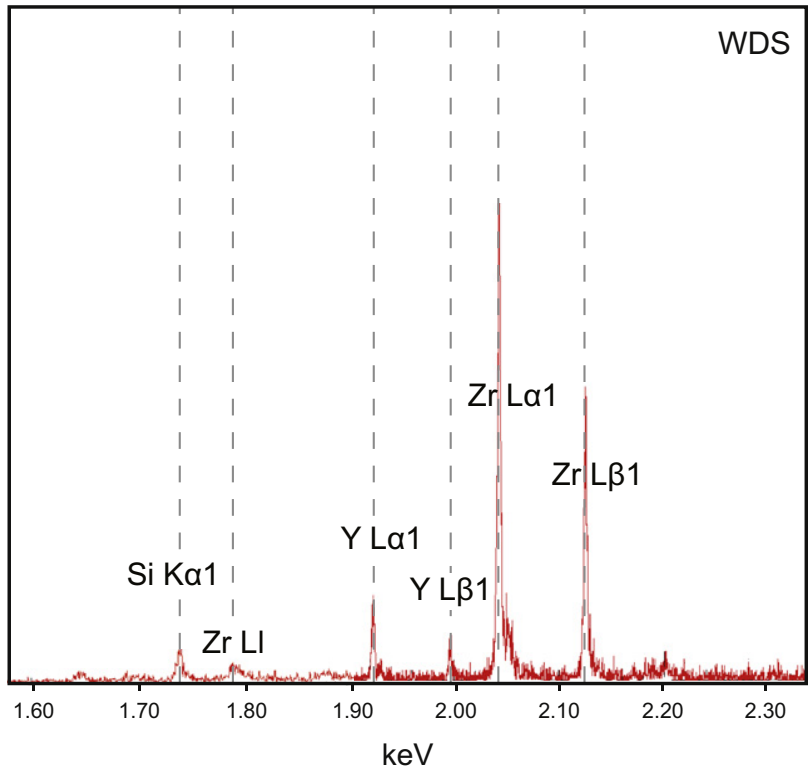

Fig. 3 - Simulated bulk sample EDS for hypothetic materials consisting of 8 YSZ containing $0.1,1$ and $10 \mathrm{~mol}^{\circ} \mathrm{SiO}_{2}(\mathrm{a})$ and WDS carried out by EPMA (b) of the Ni/YSZ electrode of the tested SOEC. The FWHM (Mn K $\alpha$ ) for the simulated spectra is $150 \mathrm{eV}$. The spectral resolution of the WDS is one magnitude higher than that for EDS. Note the peak overlap of the Si K $\alpha 1$ line and the $\mathrm{Zr} \mathrm{Ll}$ line, which confines the Si detection limit to a range of $0.1-1 \mathrm{~mol} \%$ for the simulated EDS.

segregated to the oxygen electrode/electrolyte interface, and no Si diffused into the electrolyte.

As has been previously discussed, the Si contamination most likely enters the active hydrogen electrode as gaseous $\mathrm{Si}(\mathrm{OH})_{4}$ [7]. The reduction of steam will occur close to the hydrogen electrode/electrolyte interface. This will in turn lead to the equilibrium between $\mathrm{Si}(\mathrm{OH})_{4}$ and $\mathrm{SiO}_{2}+\mathrm{H}_{2} \mathrm{O}$ being shifted towards the formation of silica. Therefore, we can expect the largest concentration of Si-containing impurities to be found closest to the hydrogen electrode/electrolyte interface, which is consistent with the obtained WDS mapping (Fig. 4). Additionally, several mappings of different sample areas were performed for the tested cell and the reference cell, showing the same results as those depicted in Fig. 4 . The $\mathrm{Si}$
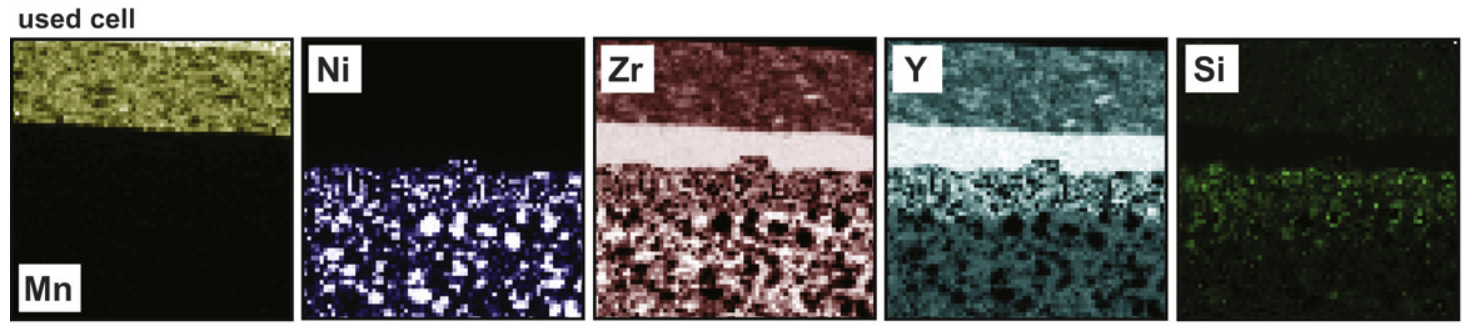

LSM/YSZ

electrode

$\bar{Y} \overline{S Z}$ electrolyte

$\overline{\mathrm{Ni}} / \mathrm{YSZ}$

electrode
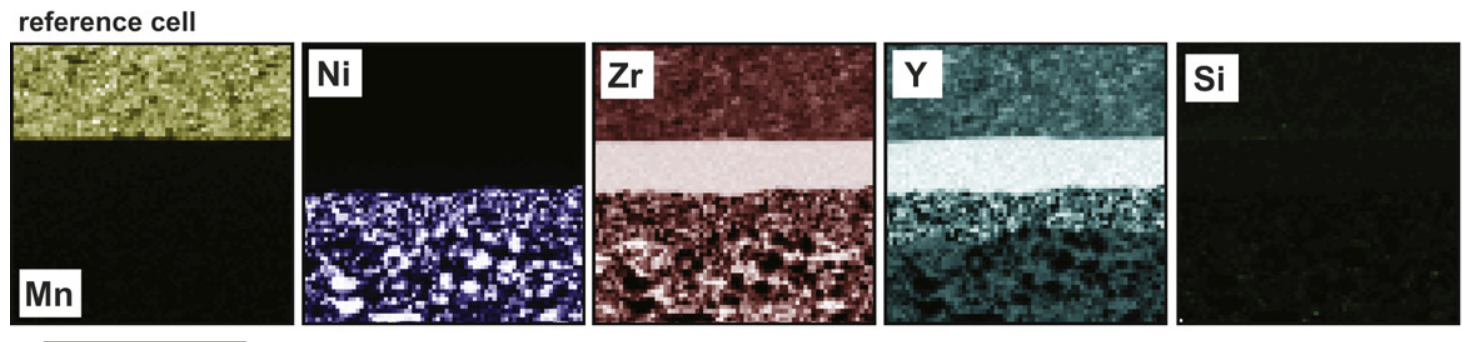

LSM/YSZ

electrode

$\bar{Y} \bar{S} Z$ electrolyte

$\mathrm{Ni} / \mathrm{YSZ}$

electrode

$50 \mu \mathrm{m}$

Fig. 4- $70 \mu \mathrm{m} \times 70 \mu \mathrm{m}$ WDS mappings of the hydrogen electrode-supported SOEC: The upper row shows the mappings of the constituent elements $\mathrm{Mn}, \mathrm{Ni}, \mathrm{Zr}$ and $\mathrm{Y}$ in a hydrogen electrode-supported SOEC produced at Risø DTU that was operated in total for $1500 \mathrm{~h}$ and for several hundreds of hours in electrolysis mode (see test B in Hauch et al. 2007a). In addition, the mapping of the impurity element $\mathrm{Si}$ is shown. The lower row shows the corresponding mappings of an unused reference cell from the same production batch. 
a

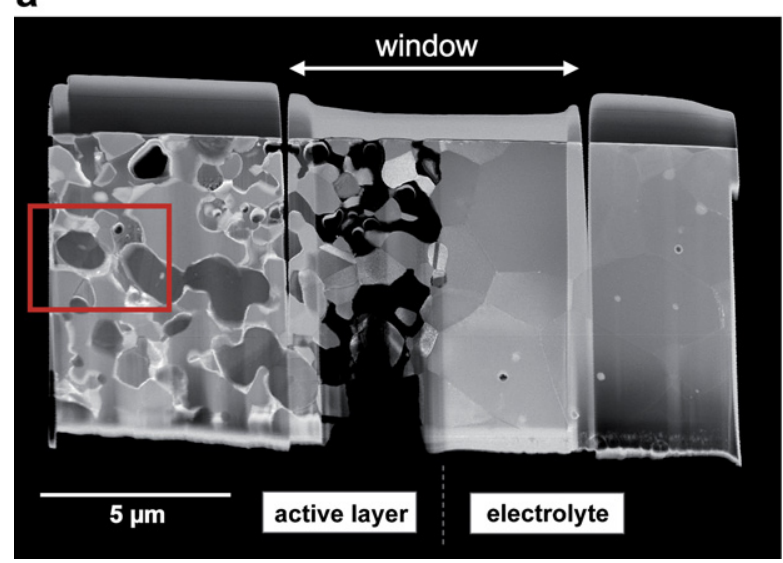

b
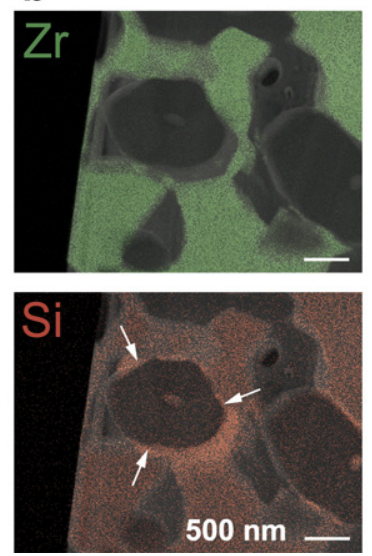
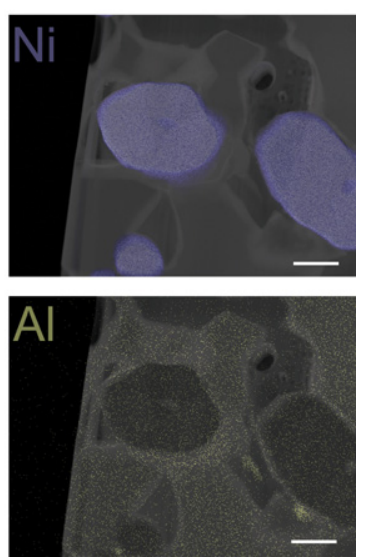

Fig. 5 - STEM/EDS examination of the electrolyte / hydrogen electrode interface in a hydrogen electrode-supported SOEC from Ris $\varnothing$ DTU. A dark-field STEM image of a TEM lamella prepared by the FIB procedure is shown (a). At the interface between the electrolyte and the hydrogen electrode, the lamella is approx. $100 \mathrm{~nm}$ thick (window). The red box indicates the region in which the EDS mappings shown in (b) were recorded. The coloured regions in the small insets (EDS mappings superimposed on a STEM image) reflect the different elements: Zr (YSZ particles, green), Ni (Ni particles, blue), Si (Si enrichment, red), Al, (Al enrichment, yellow). The arrows indicate positions, which were triple-phase boundaries of YSZ particles, Ni particles and pores before the precipitation of a Si-bearing phase. The STEM image and the mappings were recorded with a FEI CM30 / Noran detector system at $300 \mathrm{kV}$.

content (if any) in the reference cell is below the detection limit of WDS.

\subsection{Nano-scale structure and chemical composition}

While the EPMA measurements cover rather large sample areas on a microscopic level, the TEM/STEM examination of FIB-prepared thin lamellae enables us to complement these measurements by investigating site-specifical structural and chemical changes on the nanoscopic level. The TEM/STEM imaging of the hydrogen electrode/electrolyte interface affords a thorough characterisation of the critical triple-phase boundaries (TPB).

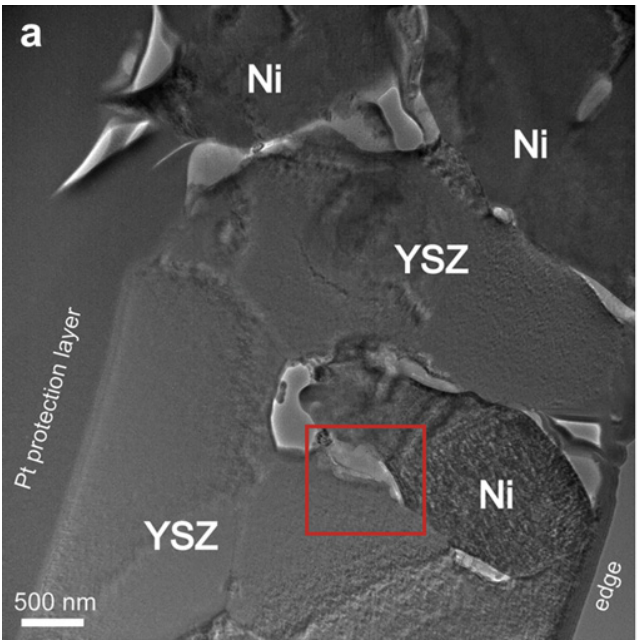

Fig. 5 shows STEM images of the entire lamella of the tested cell and a magnified image of a particular region of the lamella. EDS mapping was performed for this selected region. From the EDS map, it is evident that $\mathrm{Si}$ - and Al-containing impurities are located along the Ni/YSZ-interface as individual phases. This finding is consistent with both EPMA (Fig. 4) and SEM/EDS studies of several tested SOECs [7].

In the Si-EDS map of Fig. 5b, three arrows indicate positions in the structure, which correspond to TPBs before the precipitation of the Si-bearing phase. The electron-conducting $\mathrm{Ni}$ particle borders here with oxide-ion-conducting 8YSZ particles and open pores through which steam and hydrogen can enter and leave the electrode structure. However, as is

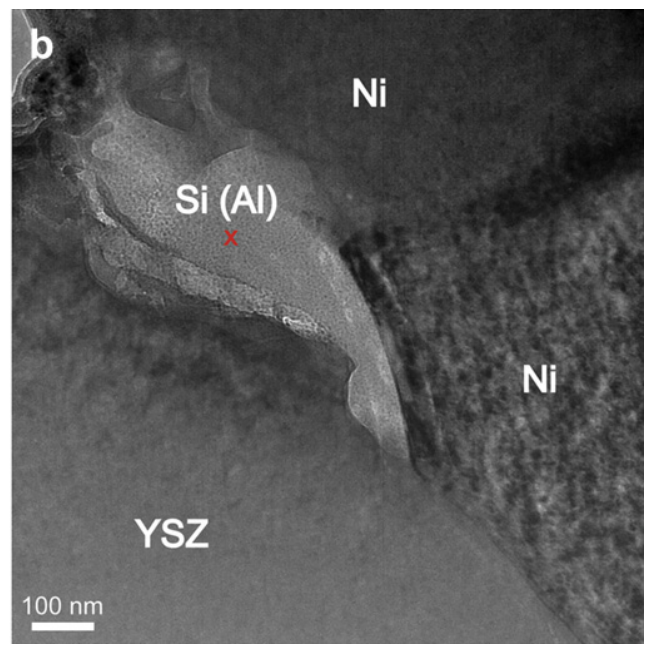

Fig. 6 - Bright-field TEM images from a FIB-prepared TEM lamella from the electrolyte/hydrogen electrode interface of the electrolysis-tested cell. The square in the overview image (a) marks the region for the high-magnification image (b), and the point for the EDS measurement referred to in the text was recorded at the spot marked $\mathrm{X}$. 
evident from the EDS mapping in Fig. 5, these TPBs are no longer directly available for the electrochemical reaction due to the deposition of impurities in the pore. Such blocking of the TPBs will lead to an undesired increase in the resistance of the cell.

The shape of the largest impurity phase shown in Fig. 5 indicates that this Si phase is not only located at the triplephase boundary, but also cover parts of the two-phase boundaries of the cermet material. Blocking of a TPB can generally be expected to increase the polarisation resistance [4]. The changes at the two-phase boundaries complicate the correlation between the impurity blocking in the electrode structure and the observed increase in polarisation resistance and possibly in the ohmic resistance obtained from impedance spectroscopy as well. Details of the electrochemical characterisation of the tested cell obtained from impedance spectroscopy are reported in [7]. An additional TEM lamella was made of the electrolyte/hydrogen electrode interface from the cell described in this study. The FIB preparation of this sample is described elsewhere [8]. An overview TEM image and an inset of an impurity phase at the hydrogen electrode/electrolyte interface are shown in Fig. 6. Quantitative EDS measurements of this TEM lamella showed impurity phases mainly consisting of silica. A typical EDS result obtained at the spot marked " $\mathrm{X}$ " in Fig. 6b showed 2.8 atom\% $\mathrm{Al}$ and 38 atom\% $\mathrm{Si}$, corresponding to a $\mathrm{SiO}_{2} / \mathrm{Al}_{2} \mathrm{O}_{3}$ ratio of approximately 7 . However, it should be noted that the alumina could originate from the alumina added during cell production as a sintering aid.

\section{Conclusion}

- Complementary microscopy and microanalysis techniques are necessary, or at least highly recommended, for comprehensive chemical and structural characterisation of SOCs at the micro- to nano-scale level.

- EDS / WDS bulk sample chemical analysis provides qualitative and semi-quantitative information at the micro-scale of the porous cermet electrodes.

- TEM lamellae were successfully prepared by a focused ion beam technique. This provided site-specific TEM lamellae of the interface of the porous and heterogeneous electrode and the dense electrolyte of solid oxide cells.

- Thin-film TEM-EDS measurements provide quantitative information, especially at the nano-scale, for the electrolyte/hydrogen interface of solid oxide cells.

- $\mathrm{SiO}_{2}$-rich and $\mathrm{Al}_{2} \mathrm{O}_{3}$-containing impurities were detected, and they were found to block triple-phase boundaries of the hydrogen electrode in consistency with the decreased cell performance observed during the long-term electrolysis testing of this solid oxide cell.

\section{Acknowledgements}

We thank co-workers at the Fuel Cell and Solid State Chemistry Division, Ris $\varnothing$ National Laboratory for Sustainable Energy, Technical University of Denmark, and co-workers at the Hydrogen and Energy Department, Empa - Materials Science \& Technology, Switzerland. We also thank Honza Catchpole and Christoph Neururer for help and comments on the manuscript. This work was financially supported by the EU via the project Hi2H2, contract no. FP6-503765.

\section{R E F E R E N C E S}

[1] Bo Y, Wenqiang Z, Jingming X, Jing C. Status and research of highly efficient hydrogen production through high temperature steam electrolysis at INET. Int J Hydrogen Energy 2009; doi:10.1016/j.ijhydene.2009.05.037.

[2] Brisse A, Schefold J, Zahid M. High temperature water electrolysis in solid oxide cells. Int J Hydrogen Energy 2008; 33:5375-82.

[3] Dönitz W, Erdle E, Streicher R. chapter 3. In: Wendt Hartmut, editor. High temperature electrochemical technology for hydrogen production. electrochemical hydrogen technologies. Elsevier; 1990.

[4] Fleig J. On the width of the electrochemically active region in mixed conducting solid oxide fuel cell cathodes. J Power Sourc 2002;105:228-38.

[5] Goldstein IJ, Newbury DE, Echlin P, Joy DC, Fiori C, Lifshin E. Scanning electron microscopy and $\mathrm{x}$-ray microanalysis. New York and London: Plenum Press; 1984.

[6] Hauch A, Ebbesen SD, Jensen SH, Mogensen M. Highly efficient high temperature electrolysis. J Mater Chem 2008;18: 2331-40.

[7] Hauch A, Jensen SH, Bilde-Sørensen JB, Mogensen M. Silicate Segregation in the Ni/YSZ Electrode. J Electrochem Soc 2007a; 154:A619-26.

[8] Hauch A, Jensen SH, Mogensen M, Kuhn LT. Scanning 2007b; 29(2):44-5.

[9] Herring JS, O’Brien JE, Stoots CM, Hawkes GL, Hartvigsen JJ, Shahnam M. Progress in high-temperature electrolysis for hydrogen production using planar SOFC technology. Int J Hydrogen Energy 2007;32:440-50.

[10] Jensen SH, Larsen PH, Mogensen M. Hydrogen and synthetic fuel production from renewable energy sources. Int J Hydrogen Energy 2007;32:3253-7.

[11] Langford R. In: Yao N, editor. Preparation for physicochemical analysis. Focused IOn beam systems: basics and application. Cambridge University Press; 2007. p. 215-49.

[12] Liu YL, Thyden K, Xing Q Johnson E. In: Proceedings of the 26th Risø international symposium on materials science: solid state electrochemistry; 2005. p. 273-78.

[13] McKellar MG, OBrien J.E, Stoots CM, Herring JS. Demonstration and system analysis of high temperature steam electrolysis for large-scale hydrogen production using SOFCs. 8th EUROPEAN SOFC Forum. Lucerne June 30 July 4; 2008.

[14] Meng N, Leung MKH, Leung DYC. Technological development of hydrogen production by solid oxide electrolyzer cell (SOEC). Int J Hydrogen Energy 2008;33:2337-54.

[15] Meusinger J, Riensche E, Stimming U. Reforming of natural gas in solid oxide fuel cell systems. J Power Sourc 1998;71:315-20.

[16] Ni M, Leung MKH, Sumathy K, Leung DYC. Potential of renewable hydrogen production for energy supply in Hong Kong. Int J Hydrogen Energy 2006;31:1401-12.

[17] Orloff J, Utlaut M, Swanson L. High-resolution focused ion beams: fib and its applications. Kluwer Academic/Plenum Publishers; 2003. Applications of focused ion beams. 205-286.

[18] Peters R, Dahl R, Klüttgen U, Palm C, Stolten D. Internal reforming of methane in solid oxide fuel cell systems. J Power Sourc 2002;106:238-44. 
[19] Phaneuf MW. In: Gianuzzi LA, Stevie FA, editors. FIB for materials science applications-A review. introduction to focused ion beams: instrumentation, theory, techniques and practice. Springer Science + Business Media; 2005. p. 143-72.

[20] Pregger T, Graf D, Krewitt W, Sattler C, Roeb M, Möller S. Prospects of solar thermal hydrogen production processes. Int J Hydrogen Energy 2009;34:4256-67.
[21] Sigurvinsson J, Mansilla C, Lovera P, Werkoff F. Can high temperature steam electrolysis function with geothermal heat? Int J Hydrogen Energy 2007;32: 1174-82.

[22] Shin Y, Park W, Chang J, Park J. Evaluation of the high temperature electrolysis of steam to produce hydrogen. Int J Hydrogen Energy 2007;32:1486-91. 